\title{
Technical note: Water vapour concentration and flux measurements with PTR-MS
}

\author{
C. Ammann, A. Brunner, C. Spirig, and A. Neftel \\ Agroscope Reckenholz-Tänikon ART, Federal Research Station, Reckenholzstrasse 191, 8046 Zürich, Switzerland
}

Received: 9 May 2006 - Published in Atmos. Chem. Phys. Discuss.: 27 June 2006

Revised: 18 September 2006 - Accepted: 12 October 2006 - Published: 17 October 2006

\begin{abstract}
The most direct approach for measuring the exchange of biogenic volatile organic compounds between terrestrial ecosystems and the atmosphere is the eddy covariance technique. It has been applied several times in the last few years using fast response proton-transfer-reaction mass spectrometry (PTR-MS). We present an independent validation of this technique by applying it to measure the water vapour flux in comparison to a common reference system comprising an infra-red gas analyser (IRGA). Water vapour was detected in the PTR-MS at mass 37 (atomic mass units) corresponding to the cluster ion $\mathrm{H}_{3} \mathrm{O}^{+} \cdot \mathrm{H}_{2} \mathrm{O}$. During a fiveweek field campaign at a grassland site, we obtained a nonlinear but stable calibration function between the mass 37 signal and the reference water vapour concentration. With a correction of the high-frequency damping loss based on empirical ogive analysis, the eddy covariance water vapour flux obtained with the PTR-MS showed a very good agreement with the flux of the reference system. The application of the empirical ogive method for high-frequency correction led to significantly better results than using a correction based on theoretical spectral transfer functions. This finding is attributed to adsorption effects on the tube walls that are presently not included in the theoretical correction approach. The proposed high-frequency correction method can also be used for other trace gases with different adsorption characteristics.
\end{abstract}

\section{Introduction}

Proton transfer reaction mass spectrometry (PTR-MS) has become widely used for the detection of biogenic volatile organic compounds (BVOC), and in the last five years it has been applied several times for respective flux measurements

Correspondence to: C. Ammann

(christof.ammann@art.admin.ch) by the eddy covariance (EC) technique (e.g. Karl et al., 2001, 2002, 2004; Schade and Custer, 2004; Lee et al., 2005; Spirig et al., 2005; Holzinger et al., 2006). Before, the EC technique had been applied only for few single organic trace gases like isoprene (Guenther and Hills, 1998). PTR-MS systems used so far for EC measurements included quadrupole mass filtering and detection of a few selected ions with an integration time between 0.2 and $1 \mathrm{~s}$. Thus, for a multi-component EC measurements with sequential detection, the effective sampling frequency for each compound becomes about $1 \mathrm{~Hz}$ or less. In addition, the sampled time series of the individual compounds are - in the strict sense - disjunct, because of the gaps during the sampling of the other compounds. As a consequence, special evaluation schemes have been used for the flux calculation, mainly the "virtual disjunct" approach (Karl et al., 2002) and a low-pass filter approach with an averaging over the unresolved high frequencies (Spirig et al., 2005). Especially for flux measurements over low vegetation, limitations in the temporal resolution of the sampling (also due to the design of the air inlet) can lead to considerable damping of the high-frequency fluctuations and an underestimation of the flux that has to be corrected for. Therefore, a validation of the measured fluxes with independent and reliable methods would be useful. However, flux measurement techniques that could serve as a reference for eddy covariance are not available, and presently there are no alternative analytical systems for BVOC with similar or better capabilities than PTR-MS.

We present here a validation of EC measurements with PTR-MS based on the water vapour flux, for which well established reference systems exist. EC flux measurements for water vapour combining a sonic anemometer and an infra-red absorption gas analyser (IRGA) are most widely used nowadays also as part of large operational measuring flux programs such as EUROFLUX (Aubinet et al., 2000). During the vegetation period 2004 we measured water vapour fluxes over an intensively managed grassland field at the Swiss CarboEurope grassland site using the PTR-MS and the IRGA

Published by Copernicus GmbH on behalf of the European Geosciences Union. 
methodology in parallel. We present an empirical correction method for the high-frequency damping effect based on ogive analysis and compare the resulting fluxes of the two methods.

\section{Methods}

\subsection{The PTR-MS instrument}

Proton-Transfer Reaction Mass Spectrometry (PTR-MS) utilizes the ionisation of air constituents by reaction with hydronium ions $\left(\mathrm{H}_{3} \mathrm{O}^{+}\right)$in a drift tube and subsequent detection of the protonated compounds by a mass selective quadrupole detector. For details of this analytical technique, the reader is referred to Lindinger et al. (1998), de Gouw et al. (2000), or Ammann et al. (2004a). The instrument used in this study was the commercially available instrument manufactured by IONICON (GmbH, Innsbruck, Austria). It features a drift tube with a small reaction volume allowing a short residence time of the sample air of only $0.1 \mathrm{~s}$. However, the effective time resolution of PTR-MS measurements is additionally limited by the integration time necessary to obtain sufficient counts of the respective ion mass.

For the instrument setup used in the present study, the signal of the primary ions $\mathrm{H}_{3} \mathrm{O}^{+}$at mass $19 \mathrm{amu}(\mathrm{m} 19)$ was in the order of $5 \times 10^{6} \mathrm{cps}$ (counts per second). For practical reasons, the $\mathrm{H}_{3} \mathrm{O}^{+}$signal was detected at mass 21 (as $\mathrm{H}_{3}^{18} \mathrm{O}^{+}$ with a constant isotope ratio of 1:500 relative to $\mathrm{m} 19)$. Observed sensitivities for BVOCs were typically in the order of $10^{2} \mathrm{cps} / \mathrm{ppb}$. The signals of product ions are proportional to the concentration of primary ions and therefore given in normalised counts per second (ncps), i.e. the counts at a specific mass per $10^{6}$ counts of the primary ions $\mathrm{H}_{3} \mathrm{O}^{+}$.

The primary hydronium ions can form clusters with water molecules present in the drift tube. The resulting cluster ions $\mathrm{H}_{3} \mathrm{O}^{+} \cdot \mathrm{H}_{2} \mathrm{O}$ are detected at mass 37 . The water molecules in the drift tube originate to one part from the neighbouring ion source volume and to another part from the water vapour in the sample air. For a given setup of the instrument it is assumed that the first $\mathrm{H}_{2} \mathrm{O}$ source is relatively constant while the second is related to the absolute humidity of the ambient air. The formation and stability of water clusters strongly depend on the conditions in the drift tube, especially on the ratio of the electric field strength $(E)$ and the gas density $(N)$. $E / N$ has to be chosen high enough to avoid excessive clustering (de Gouw et al., 2003), but on the other hand as low as possible to minimize fragmentation. During the whole measuring period we ran the PTR-MS with an $E / N$ ratio of $130 \mathrm{Td}\left(10^{-17} \mathrm{~V} \mathrm{~cm}^{2} \mathrm{molec}^{-1}\right)$ and also the other operation parameters were held constant. For this setup of the PTRMS, the $\mathrm{H}_{3} \mathrm{O}^{+} \cdot \mathrm{H}_{2} \mathrm{O}$ ion signal $\mathrm{m} 37$ is only a few percent of the un-clustered hydronium ion signal $\mathrm{m} 19$. It is expected that $\mathrm{m} 37$ has a stable quantitative relationship to the water vapour concentration of the sample air and thus can be used, with an adequate calibration, to measure the water vapour flux.

\subsection{Field site}

The experimental site is located at Oensingen in Central Switzerland $\left(47^{\circ} 17^{\prime} \mathrm{N} / 07^{\circ} 44^{\prime} \mathrm{E}\right.$; $450 \mathrm{~m}$ a.s.l.). The prevailing climate is temperate continental, with an average annual rainfall of about $1100 \mathrm{~mm}$ and a mean annual air temperature of $9^{\circ} \mathrm{C}$. The experimental plot (size $52 \times 146 \mathrm{~m}$ ) is part of a carbon and greenhouse gas budget experiment (for details see Flechard et al., 2005; Ammann et al., 2004b) and was converted from an arable rotation into permanent grassland (newly sown grass-clover mixture) in 2001. The measurements reported here were performed during the third growth period in 2004, between 25 June and 2 August. During the experiment, the grass canopy height increased from $0.08 \mathrm{~m}$ to $0.20 \mathrm{~m}$.

\subsection{Eddy covariance flux measurements}

$\mathrm{CO}_{2}$ and $\mathrm{H}_{2} \mathrm{O}$ fluxes are routinely measured at the Oensingen site by the eddy covariance (EC) technique using a combination of a sonic anemometer (HS research anemometer, Gill Instruments, Lymington, UK) and an open-path infrared gas analyser (IRGA, Li-7500, Li-Cor, Lincoln NE, USA) installed at $1.2 \mathrm{~m}$ above ground. Data of both instruments were sampled at a frequency of $20 \mathrm{~Hz}$. Details of the instrumental setup and the flux calculation procedure are given by Ammann et al. (2004b, 2006 ${ }^{1}$ ).

The EC flux measurement with the PTR-MS was done with the same sonic anemometer as for the IRGA system. Ambient air close to the sonic sensor head (distance ca. $15 \mathrm{~cm}$ ) was continuously sampled through a $30 \mathrm{~m}$ long inlet line (PFA O.D. 1/4", I.D. $3.5 \mathrm{~mm}$ ) leading to the PTRMS instrument. The inlet line was purged with a flow rate of $4 \mathrm{~L} / \mathrm{min}$, resulting in a likely laminar flow regime with a Reynolds number of 1620 and an average tube residence time (delay time between sonic wind and PTR-MS measurements) of about $4.3 \mathrm{~s}$.

The effective measurement interval of the PTR-MS of $0.7 \mathrm{~s}$ was about 14 times longer compared to the sonic/IRGA system. As the quadrupole filter only allows subsequent detection of different ion masses, the achievable time resolution decreases with the number of scanned masses. In the present study we scanned five different ion masses, allowing to measure the fluxes of three different BVOC species and of m37 (as water vapour signal). Beside $\mathrm{m} 37$ and the primary ion isotope $\mathrm{m} 21$, the ion masses $\mathrm{m} 33$ (methanol), $\mathrm{m} 45$ (acetaldehyde) and $\mathrm{m} 59$ (acetone) were detected. To determine the $\mathrm{m} 21$ and the m37 signal (both in the order of $10^{4} \mathrm{cps}$ ) an

\footnotetext{
${ }^{1}$ Ammann, C., Flechard, C., Leifeld, J., Neftel, A., and Fuhrer, J.: The carbon budget of newly established temperate grassland depends on management intensity, Agric. Ecosyst. Environ., submitted, 2006.
} 
integration interval of $50 \mathrm{~ms}$ was sufficient while for typical BVOC ambient concentrations of $1 \mathrm{ppb}$ or less, an integration time of at least $0.2 \mathrm{~s}$ was necessary to avoid significant noise attributions due to counting statistics. The resulting measurement cycle with a total interval of $0.7 \mathrm{~s}$ is illustrated in Fig. 1. Usually the PTR-MS instrument was operated in the EC mode for half an hour within each full hour.

2.4 Flux calculation and correction of high frequency losses

To calculate the fluxes we used the EC calculation method described by Spirig et al. (2005). In a nutshell: the PTR-MS measurement for an individual ion mass is regarded to be representative for the whole time period of the measuring cycle of $0.7 \mathrm{~s}$ (see Fig. 1). Technically, this is implemented by simply repeating the PTR-MS mass concentrations of a particular cycle until the next PTR-MS data point is available. After this procedure similar equidistant time series (time resolution $\Delta t=0.05 \mathrm{~s}$ ) of sonic wind data and PTR-MS data are available for the flux calculations. Following the eddy covariance method the vertical flux of a trace gas $F_{c}$ (or of another scalar quantity) is calculated as the covariance of the discrete time series of the vertical wind $w(t)$ and the concentration $c(t)$ over an averaging period $T_{a}$ of typically $30 \mathrm{~min}$ :

$F_{c}=\operatorname{cov}_{w c}\left(\tau_{\mathrm{del}}\right)=\left(\frac{\Delta t}{T_{a}}\right) \times \sum_{t=0}^{T_{a}} w(t) \times c\left(t+\tau_{\mathrm{del}}\right)$

The two time series are adjusted to each other by a delay time $\tau_{\text {del }}$ that accounts for the residence time in the air sampling tube and possible time difference between the data acquisition systems. In the present evaluation, $\tau_{\text {del }}$ was determined empirically by searching the maximum of the covariance function (within a physically plausible range). Beside the delay time, the inlet tube also led to a damping of highfrequent turbulent fluctuations of the trace gas concentrations before the detection by the PTR-MS. Additional highfrequency damping effects of the PTR-MS signals stem from the limited time resolution and the corresponding data treatment, as well as from the separation distance between the sampling tube inlet and the anemometer sensor. These damping effects can have a considerable impact on the calculated flux, especially at low measurement heights, and have to be corrected for.

Several approaches to determine the high-frequency damping effect have been proposed in the literature (for a review, see Massman and Clement, 2004), among which the "transfer function method" initiated by Moore (1986) is most widely used nowadays and is recommended in the operational procedure of large EC flux networks such as EUROFLUX (Aubinet et al., 2000). In this theoretical mechanistic approach, the frequency damping is calculated using known spectral transfer functions for each damping effect, i.e. sensor/inlet separation, radially differential flow speed

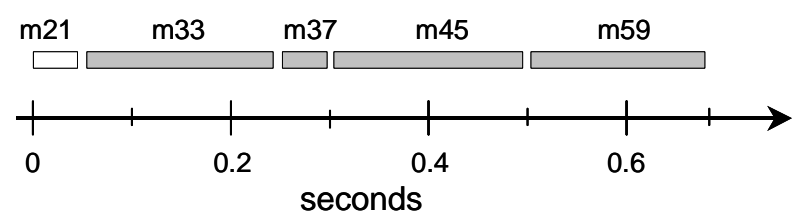

Fig. 1. Typical eddy covariance measurement cycle with dwell times of $0.2 \mathrm{~s}$ for VOC related masses and $50 \mathrm{~ms}$ for primary ions (hydronium ion isotope $\mathrm{m} 21$ and hydronium cluster ion $\mathrm{m} 37$ ).

in the sampling tube, and limited response or sampling frequency of the trace gas analyser. The transfer functions of the individual damping effects are subsequently applied to the ideal turbulent flux co-spectra after Kaimal (Kaimal et al., 1972; Kaimal and Finnigan, 1994) in order to quantify the integral flux damping factor. Beside instrument specific (quasiconstant) parameters, the transfer functions and the Kaimal spectra depend only on wind speed and for stable conditions also on stability. The problems of this theoretical approach are the ideal assumptions that are made on one hand about the shape of the co-spectra and on the other hand about the relevant damping mechanisms that have to be known a priori.

As an alternative, we developed an empirical correction approach using the spectral information of the measured time series, i.e. the flux "ogives". The ogive $O g_{w c}$ is defined as the cumulative sum of the finite co-spectrum $\mathrm{Co}_{w c}$ (Desjardins et al., 1989; Oncley et al., 1996). The co-spectrum is the real part of the discrete Fourier transform of the full covariance function $\operatorname{cov}_{w c}(t)$ with $0 \leq t \leq T_{a}$. The ogive describes the cumulative contribution to the turbulent flux of the different fluctuation frequencies in the range limited by the averaging interval $T_{a}$ and the time resolution $\Delta t$ :

$$
\begin{aligned}
O g_{w c}\left(f_{m}\right) & =\sum_{i=1}^{m} \operatorname{Co}_{w c}\left(f_{i}\right) \\
f_{i} & =\frac{i}{T_{a}} ; m=1,2, \ldots,\left[\frac{T_{a}}{2 \times \Delta t}\right]
\end{aligned}
$$

The ogive over all frequencies is equal to the eddy covariance flux $F_{c}$ (Eq. 1) of the corresponding time series. For practical purposes the ogives are normalised by $F_{c}$ to have a maximum value of 1 and they are reduced to $40-50$ data points regularly distributed over the logarithmic frequency scale. Figure 2a shows two exemplary ogives derived from sonic and PTR-MS measurements. The heat flux ogive is calculated from the sonic temperature that experienced almost no damping. This ogive shape represents the true cumulative contribution of the various frequencies to the turbulent flux. In contrast, the ogive of the m37 signal reaches the maximum value of 1 already at lower frequencies because some 

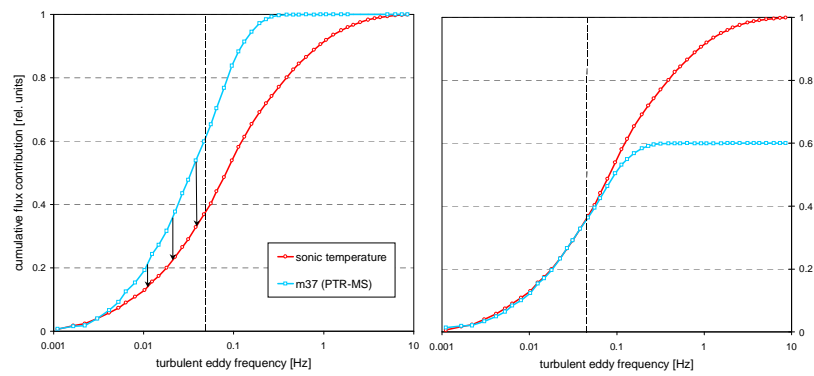

Fig. 2. Illustration of the empirical approach to determine high frequency loss based on relative flux ogives. The ogive of the damped quantity (here PTR-MS m37) is adjusted to the ogive of the almost un-damped sonic temperature in the lower frequency range (up to $0.065 \mathrm{~Hz}$ ), where almost no damping occurs. The displayed ogives represent averages over 5 half-hourly measurements at the field site on 16 July 2004 between 11:00 and 15:00.

higher frequency contributions were damped out by the measurement process. The total damping effect is determined empirically by scaling the damped ogive at the low frequencies (up to $0.065 \mathrm{~Hz}$ representing a time period of $15 \mathrm{~s}$ ) to the respective un-damped ogive of the sensible heat flux as illustrated in Fig. 2b. The damping factor is then indicated by the right-end of the adjusted ogive. In the example case it is 0.60 for the PTR-MS m37 flux.

The damping factors, empirically determined in this way for each individual half-hour flux, are relatively noisy and sometimes unusable if e.g. the reference heat flux is close to zero. Thus a correction of the fluxes with individual damping factors would increase the noise of the flux data. To overcome this problem, we made a quality selection of the damping factors and parameterised their dependence on the main influencing parameters, in particular wind speed and stability. We excluded cases with either raw $\mathrm{m} 37$ flux or sensible heat flux close to zero $\left(\left|F_{\mathrm{m} 37}\right|<0.2 \mathrm{mmol} \mathrm{m}^{-2} \mathrm{~s}^{-1}\right.$, $\left|F_{H}\right|<5 \mathrm{~W} \mathrm{~m}^{-2}$ ), or with an obvious disturbance in the lowfrequency part of the normalised ogives (value $>0.3$ at $0.002 \mathrm{~Hz}$ ). Finally all measured fluxes were corrected for the paremeterised damping factor. Beside the empirically determined damping factor, also the theoretically estimated damping factor after Moore (1986) was calculated for comparison purposes. For the PTR-MS m37 flux, it included spectral damping functions for (a) sensor separation, (b) sonic path averaging, (c) the $0.7 \mathrm{~s}$ averaging interval of the PTRMS signal, and (d) laminar flow in the sampling tube. The latter effect was described by the transfer function given by Lenschow and Raupach (1991).

\section{Results}

Figure 3 shows the time series of the normalised m37 counts together with the ambient water concentration measured by

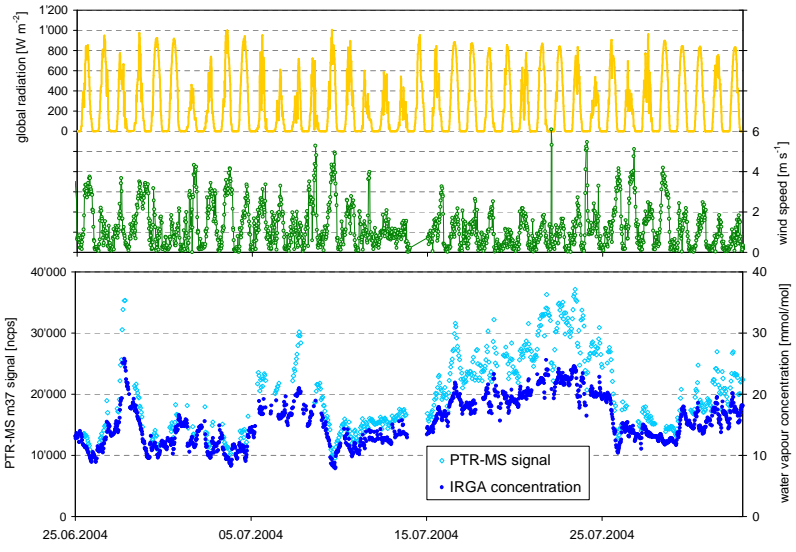

Fig. 3. (a) Time series of global radiation and wind speed for the study period; (b) time series of water vapour concentration as measured by the open-path IRGA and the normalised m37 signal detected by PTR-MS.

IRGA, as well as global radiation and wind speed for the study period that covered about five weeks (third growing period of the intensively cut grass field). A range of values between 8 and $26 \mathrm{mmol} \mathrm{mol}^{-1}$ was recorded for the water vapour. Within the measuring period we had in total 644 half hourly measurement intervals with a correct operation of the PTR-MS instrument in the EC mode. First we investigated the relationship between the normalised $\mathrm{m} 37$ signal of the PTR-MS and the water vapour concentration in the sampled air as detected by the open-path IRGA near the sampling inlet. The m37 data are plotted against the reference IRGA concentrations in Fig. 4. Because of some gaps in the IRGA data due to disturbance by rain or due formation on the openpath sensor, the number of data points for this comparison was reduced by $16 \%$ (see Table 1). The m37 signal shows a non-linear but very stable relationship to the water vapour concentration that could be well described by a 2 nd order polynomial fitted to the data by least squares regression. The resulting numerical function is also indicated in Fig. 4. The inverse of the polynomial has the form

$$
\left[\mathrm{H}_{2} \mathrm{O}\right]_{(\mathrm{mmol} / \mathrm{mol})}=0.160 \times \sqrt{[\mathrm{m} 37]_{(\mathrm{ncps})}-3764}-4.39
$$

and was used for the calibration of the m37 based water vapour concentration for the entire measurement period.

For the flux calculation and validation a more restrictive data selection was applied than for the water vapour concentration. We selected only those conditions favourable for EC flux measurements. The IRGA water vapour flux had to pass a stationarity test as described by Aubinet et al. (2000) that compares the flux values obtained with different averaging intervals. Lacking stationarity of the turbulent transport was mainly a result of breakdown of turbulence during night-time conditions with very low wind speeds that were frequently observed at our site. This selection reduced the available 
Table 1. Effect of applied selection criteria on the number of half-hourly data available for the analysis/validation of PTR-MS derived water vapour concentration, flux, and ogive/damping factor within the observation period 25 June 2004-2 August 2004.

\begin{tabular}{lcc}
\hline selection criterion & no. of data & percentage \\
\hline $\begin{array}{l}\text { correct operation of PTR-MS } \\
\begin{array}{l}\text { undisturbed IRGA conc. measurements } \\
\text { (no disturbance by rain or dew on the open-path sensor) }\end{array}\end{array}$ & 644 & $100 \%$ \\
$\begin{array}{l}\text { usable IRGA EC flux measurements } \\
\text { (acceptable stationarity of fluxes, cf. Aubinet et al., 2000) }\end{array}$ & 442 & $64 \%$ \\
$\begin{array}{l}\text { good conditions for ogive ratio calculation } \\
\text { (acceptable ogive shape, fluxes not close to zero) }\end{array}$ & 266 & $41 \%$ \\
\hline
\end{tabular}

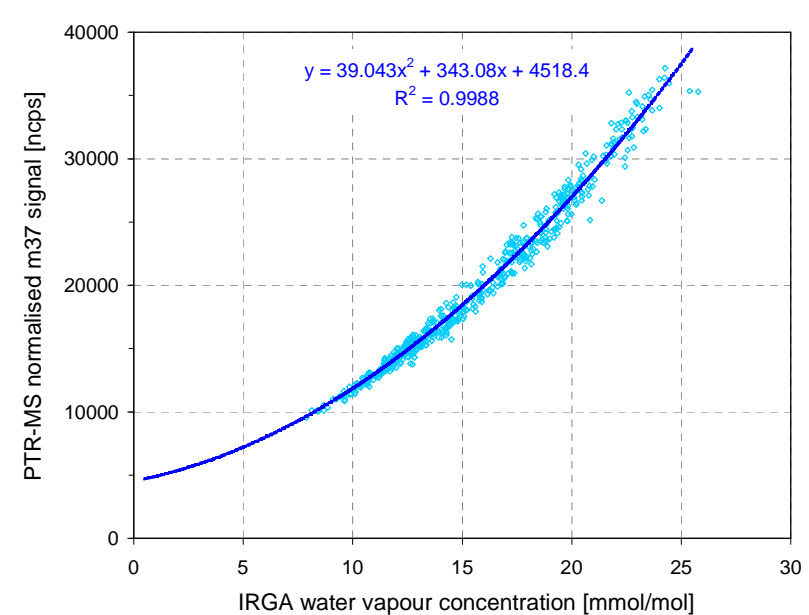

Fig. 4. Relationship between the PTR-MS m37 signal and the water vapour concentration in the sampled air as measured by the openpath IRGA. A second order polynomial fitted to the data by least square regression is indicated by the solid curve.

flux data to $69 \%$ of the original dataset (see Table 1). As described in Sect. 2.4, an additional quality selection criterion for the empirical ogives was used. With this selection, the available data points for the damping factor analysis was reduced to $41 \%$ of the raw dataset (see Table 1). The selected flux and ogive data are strongly concentrated on daytime conditions, for which more measurements were originally performed and the described rejection criteria did not apply very often.

The empirically determined damping factors for the $\mathrm{m} 37$ flux ogive (as illustrated in Fig. 2) are plotted in Fig. 5 against wind speed, which was found to be the only relevant controlling parameter in the present evaluation. The influence of stability was not significant for the mostly unstable daytime conditions. Because of the relatively large scatter of the individual data, they were grouped into wind speed classes of $0.25 \mathrm{~m} \mathrm{~s}^{-1}$ width (up to $3 \mathrm{~m} \mathrm{~s}^{-1}$ ) and of $1 \mathrm{~m} \mathrm{~s}^{-1}$ width (above

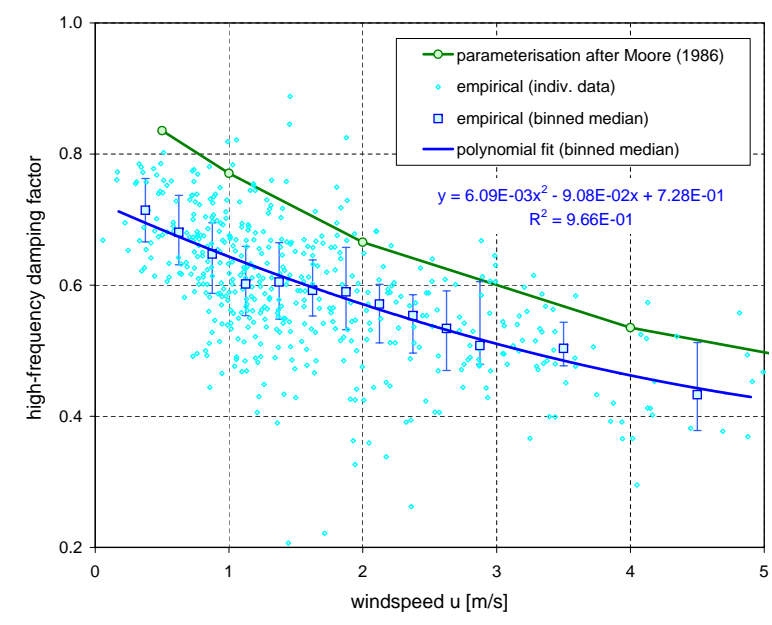

Fig. 5. Empirically determined high-frequency damping factors plotted against wind-speed. The 2 nd order polynomial fit to the median values of wind speed classes are displayed as solid curve. For comparison, the damping factor by the spectral transfer parameterisation after Moore (1986) is also shown.

$3 \mathrm{~m} \mathrm{~s}^{-1}$ ), for which the median and upper and lower quartiles were determined. A 2nd order polynomial was fitted to the median values describing the overall dependence of the empirical damping factor on wind speed. For comparison, also the theoretical damping factor resulting from the parameterisation after Moore is displayed. The theoretical damping factors are clearly higher than the empirical ones for all wind speeds.

Finally, the raw $\mathrm{m} 37$ fluxes in units of ncps $\mathrm{m} \mathrm{s}^{-1}$ were calibrated with the derivative of the nonlinear sensitivity function (Eq. 3) and the high frequency damping was corrected in two alternative ways with either the empirical ogive based polynomial function or the theoretical parameterisation displayed in Fig. 5. The resulting calibrated and corrected PTRMS based water vapour fluxes are plotted against the respective IRGA fluxes in Fig. 6. The correspondence between the PTR-MS results with the theoretical (Fig. 6a) and the 


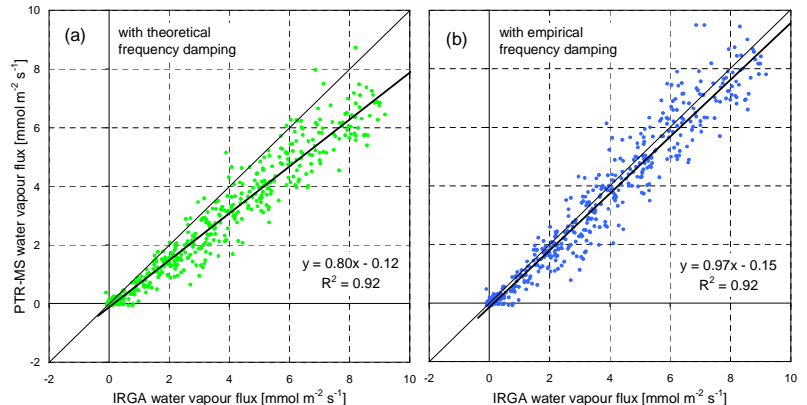

Fig. 6. Comparison of water vapour fluxes obtained with PTR-MS and open-path IRGA. Only quality checked IRGA data $(n=450)$. (a) PTR-MS flux with theoretical high-frequency correction after Moore (1986); (b) PTR-MS flux with empirical high-frequency correction.

empirical (Fig. 6b) high-frequency correction is analyzed by means of simple linear regression. For the latter case a very good agreement is found with a slope of $0.97 \pm 0.03$, an offset of $0.15 \pm 0.12 \mathrm{mmol} \mathrm{m}^{-2} \mathrm{~s}^{-1}$, and a correlation $r^{2}$ of 0.92 . If, on the other hand, the Moore algorithm with a priori assumed transfer functions and Kaimal spectra is used for the damping correction, the slope drops to $0.80 \pm 0.02$ pointing to a systematic underestimation of the damping factor.

\section{Discussion}

4.1 Water vapour concentration and flux measurements by PTR-MS

The relationship between the PTR-MS m37 cluster ion signal and the water vapour concentration during the present field experiment could be well described by a 2 nd order polynomial fit function (Fig. 4). During the reported observation period, it did not show any drift with time, but it is valid only for the constant setup of the PTR-MS instrument used here. The choice of a second order polynomial as fitting function was somewhat arbitrary and in the strict sense it is only valid within the range of the observed concentrations. Yet, calibration tests in the laboratory with similar $E / N$ setting showed the same shape of the m37 signal as displayed in Fig. 4 (including the extrapolated parts of the fitted polynomial) with dry air offset signals of 3000-5000 ncps and an increase of the curve slope with increasing water vapour concentration. The latter effect was interpreted by Steinbacher et al. (2004) as a result of the collision induced cluster dissociation between drift-tube and quadrupole unit. However, for $E / N$ values significantly lower than the $130 \mathrm{Td}$ used here, the dependence of $\mathrm{m} 37$ on the water vapour concentration was found to change its shape considerably (see also de Gouw et al., 2003). It is therefore important to perform an individual cali- bration for each instrumental setup and/or measurement campaign and to keep the setup constant as far as possible.

In combination with the empirical high-frequency correction (discussed below), the calibrated $\mathrm{m} 37$ signal yielded water vapour fluxes that were highly comparable to the results of the reference system. The slope and offset in Fig. 6b showed only very minor deviations from the ideal 1:1 line and thus no indication for a systematic difference to the reference fluxes. In particular, the small offset results from few data points with zero $\mathrm{m} 37$ flux and non-zero but small IRGA flux. The scatter of individual half-hourly data points around the regression line shows a random-like distribution with a standard deviation of the residuals of $0.7 \mathrm{mmol} \mathrm{m}^{-2} \mathrm{~s}^{-1}$. For the upper flux range $\left(5-10 \mathrm{mmol} \mathrm{m}^{-2} \mathrm{~s}^{-1}\right)$ the scatter of the residuals corresponds to a relative $2 \sigma$-precision of about $20 \%$.

In contrast to the adequate corrections of high-frequency loss, the theoretical Moore algorithm, taking into account only the known physical damping effects, yields a slope of only 0.80 that indicates a considerable systematic underestimation of the water vapour flux. This finding supports the usefulness of our empirical correction approach based on ogive analysis for an adequate correction for high-frequency loss and for identifying potentially unknown but relevant damping effects.

\subsection{Analysis of high frequency damping}

The effect of high frequency damping on the PTR-MS measurements was empirically evaluated using the comparison of the ogives (cumulative co-spectra) of the sensible heat flux and the PTR-MS water vapour flux. Since only relative ogive values are used, they may be calculated from the raw data without full calibration. The empirical ogive approach assumes an originally equal spectral distribution of the water vapour and sensible heat flux, negligible damping for the heat flux measurement, and that damping of the water vapour flux measurement only starts at frequencies exceeding $f_{\text {limit }}=0.065 \mathrm{~Hz}$ corresponding to a period of $15 \mathrm{~s}$. The frequencies below this limit contributed typically around $40 \%$ to the undisturbed heat flux and $60 \%$ to the damped water vapour flux (see Fig. 2). Since the turbulence spectra as well as the transfer functions depend on the measurement height and the wind speed (Moore, 1986; Kaimal and Finnigan, 1994), it may be necessary and useful to adapt the frequency range used for the ogive scaling when the method is applied to other sites and damping conditions. Our recommendation is to choose $f_{\text {limit }}$ equal or lower than the frequency at which the damped ogive reaches a value of $0.6-$ 0.7 in order to ensure that it is still in the undisturbed range. In cases where non-stationarity is a problem it might also be suitable to subtract the very low frequent contributions (e.g. below $0.002 \mathrm{~Hz}$ ) from the ogives before the scaling is performed. 


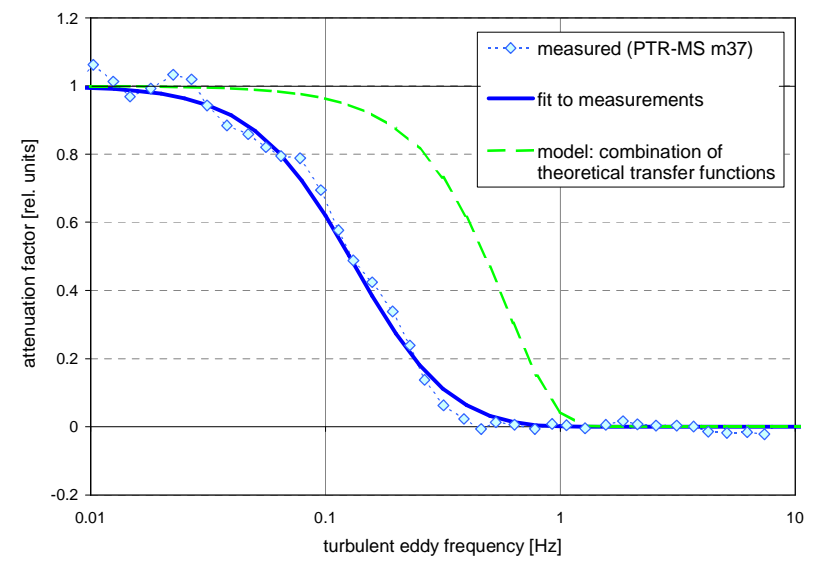

Fig. 7. Comparison of theoretical and empirical total transfer function describing the high-frequency damping effect on the PTR-MS m37 flux. The empirical curve was derived from average ogives of 5 half-hourly measurements at the field site on 16 July 2004 between 11:00 and 15:00 (same as in Fig. 2). The modelled curve is the product of known theoretical transfer functions for laminar tube flow, sensor separation, and block averaging over the PTR-MS sampling interval of $0.7 \mathrm{~s}$ according to Moore (1986).

The damping correction as calculated by the theoretical Moore approach is weaker than the empirically determined one (Fig. 5) and leads to a corresponding underestimation of the water vapour flux (Fig. 6). Since no systematic difference between the empirical and theoretical co-spectra was found (not shown here), the reason for the discrepancy must be an important damping process that has not been considered in the theoretical approach. In order to characterize this effect, the average empirical spectral transfer function (ratio between damped and undamped ogive) is displayed in Fig. 7 for an exemplary day together with the total transfer function of all known damping effects. The observed empirical transfer function can be well described by a first order response function of the following form (Horst, 1997; Su et al., 2004):

$$
H_{w c}(f) \equiv \frac{C o_{w c}(f)_{\text {damped }}}{C o_{w T}(f)_{\text {undamped }}}=\frac{1}{1+\left(2 \pi \times \tau_{d} \times f\right)^{2}}
$$

The characteristic response time $\tau_{d}$ resulting from the fit in Fig. 7 is $1.2 \mathrm{~s}$. The transfer function found for our system is very similar to empirical transfer functions reported by Goulden et al. (1996), Laubach and Teichmann (1996), Leuning and Judd (1996), and Su et al. (2004) for water vapour flux measurements with closed path systems using a long inlet tube (materials: polyethylene or Teflon). They all applied a combined $\mathrm{CO}_{2} / \mathrm{H}_{2} \mathrm{O}$ IRGA instrument for the water vapour detection and observed the strong damping effect only for the $\mathrm{H}_{2} \mathrm{O}$ and not for the $\mathrm{CO}_{2}$ flux. Thus we follow their conclusions and also attribute the strong damping effect in our system to adsorption and desorption processes of water molecules on the inner walls of the sampling

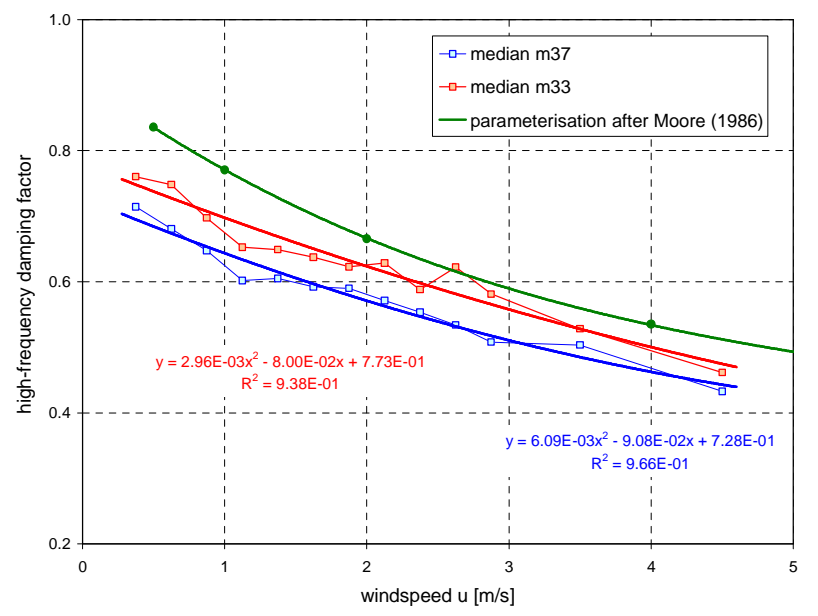

Fig. 8. Same as Fig. 5 with individual data points omitted. In addition, the empirically determined median damping factors for m33 (methanol) and the corresponding polynomial fit are displayed.

tube. Some of the authors also reported that the strength of the damping effect depended on the length of operation of the inlet tube and that it could be reduced by cleaning of the inner surfaces. Su et al. (2004) obtained $\tau_{d}$ values for the $\mathrm{H}_{2} \mathrm{O}$ flux between about $0.5 \mathrm{~s}$ and $4.6 \mathrm{~s}$ for new/cleaned and aged sampling tubes, respectively. These values were always higher than for the simultaneously measured $\mathrm{CO}_{2}$ flux with a relatively constant $\tau_{d}$ of only about $0.3 \mathrm{~s}$. Thus water vapour obviously experiences always an additional tube related damping compared to inert trace gases but the magnitude of this effect depends on the age and cleanness of the tube walls. Leuning and Judd (1996) explain this behaviour with the gradual deposition of salt crystals and other small hydrophilic particles, which are able to pass the inlet filter, onto the inner tube wall during operation. A heating of the inlet line could probably reduce the sorption effects. In the present study it was not used because it had been found to cause contamination with VOCs, possibly as a consequence of volatiles from the insulation diffusing through the PFA walls.

\subsection{Implication for BVOC measurements}

The main application purpose of the PTR-MS is the measurement of BVOC concentrations and fluxes. Therefore it is of special interest whether the damping effects quantified for water vapour also apply to the measured BVOC components. In the present study methanol (ion mass $\mathrm{m} 33$ ) was the only component with fluxes large enough to allow the determination of empirical damping factors from ogive analysis in a similar quality as for $\mathrm{m} 37$. Figure 8 shows the results of the empirical damping factors in comparison with the results for $\mathrm{m} 37$ and of the theoretical approach already discussed above. On average the empirical ogive analysis shows 
weaker high-frequency damping for methanol than for water vapour, but still stronger than predicted by the theoretical transfer functions. This indicates a smaller but still relevant wall sorption effect for methanol. For other BVOCs the effect presumably varies depending on the volatility, polarity, and water solubility properties of the individual compound. Since the "stickiness" of methanol is considered to be high, the effect for other light-weight compounds of interest, like acetaldehyde or acetone, is supposed to be of similar magnitude or even lower. However, for eddy covariance flux measurements, an empirical ogive analysis is recommended for each individual component whenever possible.

\section{Conclusions}

During a five week field measurement campaign at a grassland site we measured water vapour concentrations and eddy covariance fluxes using the PTR-MS instrument and a standard reference system based on an IR gas analyser. We obtained a non-linear but stable calibration function between the m37 signal of the PTR-MS and the water vapour concentration. With a correction of the high-frequency damping loss based on empirical ogive analysis, the water vapour flux obtained with the PTR-MS showed a very good agreement with the IRGA system. This positive validation for the $\mathrm{H}_{2} \mathrm{O}$ flux also supports the ability of the PTR-MS for adequate eddy flux measurements of various volatile organic compounds (e.g. Karl et al., 2001, 2004; Spirig et al., 2005), for which no independent validation is possible.

The application of the empirical ogive method for highfrequency correction led to significantly better results than using the correction based on theoretical spectral transfer models (e.g. Moore, 1986). This finding is attributed to adsorption effects on the tube walls that are presently not included in the models, since they are difficult to describe mechanistically and they may depend on the characteristics of the trace gas and the tube material and state (Su et al., 2004). Therefore the empirical determination and correction of high-frequency damping effects is particularly advantageous for closed-path systems with longer intake tubes and for trace gases with a high wall adsorption capacity like water vapour.

Acknowledgements. This work was financially supported by the Swiss National Science Foundation (Project COGAS, Nr. 200020-101636).

Edited by: A. B. Guenther

\section{References}

Ammann, C., Spirig, C., Neftel, A., Steinbacher, M., Komenda, M., and Schaub, A.: Application of PTR-MS for Measurements of Biogenic VOC in a Deciduous Forest, Int. J. Mass Spectrom., 239, 87-101, 2004a.

Ammann, C., Flechard, C. R., Fuhrer, J., and Neftel, A.: Greenhouse gas budget of intensively and extensively managed grassland, in: Land Use Systems in Grassland Dominated Regions, edited by: Lüscher, A., Jeangros, B., Kessler, W., et al., 130132, vdf Hochschulverlag, Zürich, 2004b.

Aubinet, M., Grelle, A., Ibrom, A., et al.: Estimates of the annual net carbon and water exchange of forests: the EUROFLUX methodology, Adv. Ecol. Res., 30, 113-171, 2000.

de Gouw, J. A., Howard, C. J., Custer, T. G., Baker, B. M., and Fall, R.: Proton-transfer chemical ionization mass spectrometry allows real-time analysis of volatile organic compounds released from cutting and drying of crops, Environ. Sci. Technol., 34, 2640-2648, 2000.

de Gouw, J., Warneke, C., Karl, T., Eerdekens, G., van der Veen, C., and Fall, R.: Sensitivity and specificity of atmospheric trace gas detection by proton-transfer-reaction mass spectrometry, Int. J. Mass Spectrom., 223/224, 365-382, 2003.

Desjardins, R. L., MacPherson, J. I., Schuepp, P. H., and Karanja, F.: An evaluation of aircraft flux measurements of $\mathrm{CO}_{2}$, water vapor and sensible heat, Boundary-Layer Met., 47, 55-69, 1989.

Flechard, C. R., Neftel, A., Jocher, M., Ammann, C., and Fuhrer, J.: Bi-directional soil/atmosphere $\mathrm{N}_{2} \mathrm{O}$ exchange over two mown grassland systems with contrasting management practices, Global Change Biol., 11(12), 2114-2127, 2005.

Goulden, M. L., Munger, J. W., Fan, S.-M., Daube, B. C., and Wofsy, S. C.: Measurements of carbon sequestration by longterm eddy covariance: methods and a critical evaluation of accuracy, Global Change Biol., 2, 169-182, 1996.

Guenther, A. B. and Hills, A. J.: Eddy covariance measurement of isoprene fluxes, J. Geophys. Res., 103, 13 145-13 152, 1998.

Holzinger, R., Lee, A., McKay, M., and Goldstein, A. H.: Seasonal variability of monoterpene emission factors for a Ponderosa pine plantation in California, Atmos. Chem. Phys, 6, 1267-1274, 2006.

Horst, T. W.: A simple formula for attenuation of eddy fluxes measured with first-order-response scalar sensors, Boundary-Layer Met., 82, 219-233, 1997.

Kaimal, J. and Finnigan, J.: Atmospheric boundary layer flows: Their structure and measurement, Oxford University Press, Oxford, 1994.

Kaimal, J. C., Wyngaard, J. C., Izumi, Y., and Coté, O. R.: Spectral characteristics of surface-layer turbulence, Q. J. R. Meteorol. Soc., 98, 563-589, 1972.

Karl, T., Guenther, A., Lindinger, C., Jordan, A., Fall, R., and Lindinger, W.: Eddy covariance measurements of oxygenated volatile organic compound fluxes from crop harvesting using a redesigned proton-transfer-reaction mass spectrometer, J. Geophys. Res., 106, 24 157-24 167, 2001.

Karl, T. G., Spirig, C., Rinne, J., Stroud, C., Prevost, P., Greenberg, J., Fall, R., and Guenther, A.: Virtual disjunct eddy covariance measurements of organic compound fluxes from a subalpine forest using proton transfer reaction mass spectrometry, Atmos. Chem. Phys., 2, 279-291, 2002,

http://www.atmos-chem-phys.net/2/279/2002/. 
Karl, T., Potosnak, M., Guenther, A., Clark, D., Walker, J., Herrik, J. D., and Geron, C.: Exchange processes of volatile organic compounds above a tropical rain forest: Implications for modeling tropospheric chemistry above dense vegetation, J. Geophys. Res., 109, D18306, doi:10.1029/2004JD004738, 2004.

Laubach, J. and Teichmann, U.: Measuring energy budget components by eddy correlation: Data corrections and application over low vegetation, Beitr. Phys. Atmosph., 69, 307-320, 1996.

Lee, A., Schade, G. W., Holzinger, R., and Goldstein, A. H.: A comparison of new measurements of total monoterpene flux with improved measurements of speciated monoterpene flux, Atmos. Chem. Phys, 5, 505-513, 2005.

Lenschow, D. H. and Raupach, M. R.: The attenuation of fluctuations in scalar concentrations through sampling tubes, J. Geophys. Res., 96, 15 259-15 268, 1991.

Leuning, R. and Judd, M. J.: The relative merits of open- and closed-path analysers for measurement of eddy fluxes, Global Change Biol., 2, 241-253, 1996.

Lindinger, W., Hansel, A., and Jordan, A.: On-line monitoring of volatile organic compounds at pptv levels by means of ProtonTransfer-Reaction Mass Spectrometry (PTR-MS), Medical applications, food control and environmental research, Int. Journal of Mass Spect. and Ion Processes, 173, 191-241, 1998.

Massman, W. and Clement, R.: Uncertainty in eddy covariance flux estimates resulting from spectral attenuation, in: Handbook of Micrometeorology, edited by: Lee, X., Massmann, W., and Law, B., 67-99, Kluwer Academic Publishers, Dordrecht, 2004.
Moore, C. J.: Frequency response correction for eddy correlation systems, Boundary-Layer Meteorol., 37, 17-35, 1986.

Oncley, S. P., Friehe, C. A., Larue, J. C., Businger, J. A., Itsweire, E. C., and Chang, S. S.: Surface-layer fluxes, profiles, and turbulence measurements over uniform terrain under near-neutral conditions, J. Atmos. Sci., 53, 1029-1044, 1996.

Schade, G. W and Custer, T. G.: OVOC emissions from agricultural soil in northern Germany during the 2003 European heat wave, Atmos. Environ., 38, 6105-6114, 2004.

Spirig, Ch., Neftel, A., Ammann, C., Dommen, J., Grabmer, W., Thielmann, A., Schaub, A., Beauchamp, J., Wisthaler, A., and Hansel, A.: Eddy covariance flux measurements of biogenic VOCs during ECHO 2003 using proton transfer reaction mass spectrometry, Atmos. Chem. Phys, 5, 465-481, 2005.

Steinbacher, M., Dommen, J., Ammann, C., Spirig, Ch., Neftel, A., and Prévôt, A. S. H.: Performance Characteristics of a ProtonTransfer-Reaction Mass Spectrometer (PTR-MS) derived from laboratory and field measurements, Int. J. Mass Spectrom., 239, 117-128, 2004.

Su, H.-B., Schmid, H. P., Grimmond, C. S. B., Vogel, C. S., and Oliphant, A. J.: Spectral characteristics and correction of longterm eddy covariance measurements over two mixed hardwood forests in non-flat terrain, Boundary-Layer Meteorol., 110, 213253, 2004. 